\title{
nature
}

28 February 2002 Volume 415 Issue no 6875

\section{A blast from the past}

NASA is right to invest heavily in nuclear propulsion to speed the progress of future missions to the outer planets. But it may pay to complete our initial exploration of the Solar System the old-fashioned way.

l: t seems unfair to call the Cassini space probe — celebrated in this week's issue (see pages 965-966 and 985-1005) — a relic of the past when it is still two years away from the encounter with Saturn that is its raison d'être.

Cassini is the most capable deep-space explorer ever launched, with optics and science instruments that are far superior to those on board its predecessors, such as the Galileo mission to Jupiter and its moons. The show from Saturn and its mysterious, cloud-covered moon Titan should be spectacular. And, unlike Galileo, Cassini isn't crippled by a broken antenna, so we should receive every byte of data that its design engineers planned for.

Still, the \$3.5-billion, six-tonne Cassini is like a 1959 Cadillac: heavy, expensive and a thing of beauty - but outdated. We would do things differently today than we did in 1989, when the project left the drawing board.

Just how differently was hinted at earlier this month, when NASA announced its plan to invest substantially in space nuclear propulsion for the first time in years. This is great news for planetary science. New propulsion systems could dramatically cut travel times to the outer planets and enable an exciting new class of missions, such as placing an orbiter around Europa, the possibly life-bearing moon of Jupiter.

Caught between the old and new ways of doing business is NASA's proposed mission to Pluto, which, like Titan, is one of the Solar System's last bits of true terra incognita. The agency has been struggling for nearly a decade with the problem of how best to explore this distant world. Last year, at the US Congress's insistence, it chose a concept called New Horizons, which uses conventional rocket propulsion, for a launch in 2006. Now that plan is on hold, while NASA revamps its outer-planets programme to incorporate possible new propulsion technologies and waits for scientific advice on which planetary targets are the most attractive.

A mission to Pluto and the Kuiper Belt - the vast population of chunks of rock and ice that lies beyond the orbit of Neptune - is likely to be high on that list. But tempting though it may be to speed up the journey with nuclear rockets, it may ultimately make more sense to stay with the proposal already on the table. A revolutionary new propulsion system will take several years to develop and test in space. And while a nuclear rocket would be fast, reaching Pluto in as little as five years, it would not be cheap.

Meanwhile, the New Horizons team has cut its proposed travel time to under ten years, and would spend less than $\$ 500$ million well below the $\$ 650$-million cap for the new breed of outer planetary missions. So while NASA should vigorously pursue the nuclear option, the best way to reach the last uncharted planet, at least in the short term, is probably still the old-fashioned way.

\section{Burdened by expectation}

Japan is asking too much of its latest flagship initiative in the biological sciences.

$B$ y any reckoning, the Center for Developmental Biology (CDB) that is soon to open its doors in Kobe, Japan (see pages 952-953), is a bold initiative. Its facilities are second to none, and its leaders have pledged to give talented young scientists free rein to develop their own research interests. Given that rigid academic hierarchies have repeatedly been blamed for Japan's perceived underachievement in basic science, expectations are high.

The danger, however, is that they may be too high, and that the $\mathrm{CDB}$ will be pressured into trying to advance on more fronts than is reasonable.

Increasingly, for instance, Japan has made overtures to recruit scientists from overseas, especially from the West, with limited success. The CDB aims to have a large number of foreigners on its roster, but this may not be a wise place to focus its efforts. There are many obstacles beyond the institute's control, such as language, a dearth of reasonably priced international schools, and fears that women will not be treated as equals.

The CDB also has to deal with the short-term vision of the current government, which wants the institute to become the hub of a cluster of bioscience companies. This is a laudable aim — but again, the CDB may have its work cut out achieving this goal.

There are many who feel that, lacking the freewheeling entrepre- neurial spirit that pervades the labs of California, Japan will never boast a vibrant biotech industry.

The CDB's director, Masatoshi Takeichi, is already worried that short-term pressures will encourage the centre's scientists to shoot for some headline-grabbing discovery, rather than building the solid foundations of a project that will truly advance their field.

Rather than worrying about the initial roster of foreign recruits, or fretting about commercial spin-offs, the CDB's paymasters would be wise to back Takeichi in his goal of making the CDB into a world leader in advancing the fundamental scientific knowledge needed to underpin the emerging field of regenerative medicine. A reasonable target would be to aim to produce a defined number of landmark papers in areas such as stem-cell biology, transgenic technology, wound healing and cellular imaging.

If the CDB can establish a reputation for excellence in these areas, and its group leaders can resist the temptation to become as autocratic with their own charges as their professors may in the past have been with them, there may no longer be a need to worry about meeting a quota of foreigners. And if young researchers from around the world are then inspired to beat a path to the CDB's door, they may also bring with them some of the entrepreneurial skills that the Japanese government is so keen to promote. 